\title{
OS DIREITOS E GARANTIAS DOS REFUGIADOS LGBTS NA ATUALIDADE
}

\section{THE RIGHTS AND GUARANTEES OF LGBT REFUGEES IN THE PRESENT}

\author{
Jamile Gonçalves Calissi ${ }^{1}$ \\ Cristina Veloso de Castro ${ }^{2}$ \\ Edmundo Alves de Oliveira ${ }^{3}$
}

RESUMO: $O$ presente artigo diz respeito aos refugiados LGBTs na contemporaneidade e em nível global. Respostas para as perguntas de quem são eles, quais os órgãos de proteção aos mesmos, quais são os direitos e garantias fundamentais oferecidas a essa população e os casos concretos que ilustram o assunto, além de dados e informações que, numérica e concretamente, mostrem a quantidade de pessoas que sobrevivem diante desta situação e circunstâncias, são encontradas na referida pesquisa. $O$ objetivo principal é explanar e informar à comunidade em geral, e, principalmente, à acadêmica, acerca do tema, a fim de darIhe conhecimento amplo, já que não é comumente tratado. O estudo possui um caráter qualitativo, em que foram colhidas sobre a matéria em questão tudo o que se precisa saber para entendê-la e formar um alicerce textual, conjuntamente ao uso do método

\footnotetext{
${ }^{1}$ Doutorado e Mestrado (Bolsista Integral CAPES) em Direito Constitucional pela Faculdade de Direito de Bauru (CEUB-ITE). MBA em Gestão Empresarial pela Fundação Getúlio Vargas. Graduação em Direito pelas Faculdades Integradas de Jaú - Fundação Educacional Dr. Raul Bauab. Professora de Educação Superior, Nível IV - Grau A, do quadro de pessoal da Universidade do Estado de Minas Gerais, Unidade Ituiutaba. Coordenadora do grupo de Pesquisa em Direito Constitucional Contemporâneo, Constitucionalismo Global e Globalização da Universidade do Estado de Minas Gerais (UEMG), jamile.calissi@uemg.br. Professora Titular no Mestrado Profissional em Direito e Gestão de Conflitos da Universidade de Araraquara (UNIARA), jgcalissi@uniara.edu.br. Professora das Faculdades Integradas de Jaú - Fundação Educacional Dr. Raul Bauab.

2 Pós-doutorado em Direito e Saúde, pela Universidade de Messina, Itália. Doutorado em Direito Constitucional pela Faculdade de Direito de Bauru (CEUB-ITE). Professora do Programa de PósGraduação Stricto Sensu em Ciências Ambientais da Universidade Brasil - Campus de Fernandópolis. Professora de Direito Constitucional na Universidade do Estado de Minas Gerais - UEMG.

${ }^{3}$ Doutorado e Mestrado em Sociologia, Especialização em Administração Pública e Graduação em Ciências sociais - Licenciatura e Bacharelado, além de diversos curso de aperfeiçoamento (1996-2002). Tem experiência docente desde 1998, em diversas instituições de Ensino Superior Particulares, além da UNESP de Araraquara e UFSCAR. Tem Experiência de pesquisas (financiadas pelo Cnpq, Capes e Funadesp) na área de Ciências Sociais Aplicada, com ênfase em Análise de Políticas Públicas e Processo Decisório e Gerencial, bem como, desenvolveu pesquisas sobre a temática da violência infanto-juvenil e identidade ético-racial. Atualmente é Coordenador do Programa de Mestrado em Direito- Gestão de Conflitos da Universidade de Araraquara- UNIARA, Coordenador Geral do NEAD da Universidade de Araraquara, Coordenador do Núcleo de Estudos Afro-Brasileiros (NEAB/UNIARA). Professor do Programa de Mestrado em Educação da Universidade de Araraquara e Professor titular da Graduação da Universidade de Araraquara. Atuou como membro da CPA e do Comitê de Ética em Pesquisa. Foi membro da Coordenação editorial da revista Cadernos de Campo- UNESP. É autor de livros e artigos em livros, revistas e jornais. Atua como Membro do Conselho Municipal de Segurança de Araraquara e desenvolve atividades junto a ONGs que tratam de Políticas Públicas e da questão da exclusão social.
} 
bibliográfico-teórico e o caráter dedutivo, usando-se fontes de pesquisa tanto primária quanto secundária.

PALAVRAS-CHAVE: Atualidade. LGBTs. Refugiados

ABSTRACT: This article concerns LGBT refugees in contemporary times and globally. Answers to the questions of who they are, which bodies are protected, what are the fundamental rights and guarantees offered to this population and the concrete cases that illustrate the subject, as well as data and information that numerically and concretely show the number of people who survive in this situation and circumstances, are found in this research. The main objective is to explain and inform the community in general, and especially the academic, about the subject in order to give you wide knowledge, since it is not commonly treated. The study has a qualitative character, in which everything that one needs to know in order to understand it and to form a textual foundation, together with the use of the bibliographic-theoretical method and the deductive character, were taken on the matter in question, using sources of both primary and secondary.

KEYWORDS: LGBT. Refugees. Present.

\section{INTRODUÇÃO}

A dinâmica e a liquidez que se encontra no mundo atualmente, advindas das rápidas transições, sejam elas sociais, econômicas, ambientais - entre outras que existem -, tem dado ao ser humano o curto espaço de tempo para tomar decisões que interferirão em suas vidas, além de outras ao seu redor, que, por motivo ou outro, estão interligadas as deles. Isso significa que, por assumir determinadas posturas ou atos, estes se farão causadores, imediatamente ou a longo prazo, de consequências perceptíveis.

É o que se percebe no exemplo dos refugiados. Desde séculos atrás, aqueles que procuram refúgio em nações, que não são as deles próprias, vêm sofrendo duras penas, e até mesmo sanções, por terem que se mudar, sem alguns casos, definitivamente, de seu lugar de origem, para se proteger de perigos iminentes a sua própria segurança. Tais perigos advêm da própria sociedade, ou até mesmo daquele que possui o poder e dever de resguardá-los: o Estado. 
E é justamente neste aspecto que deve ser feita a analogia ao primeiro parágrafo. Decisões tomadas, que nem sempre agradam a todos, e de maneira veloz - partindo da premissa que hoje vivemos em mundo globalizado, sendo cada segundo muito importante para o desenvolvimento e evolução mundial - faz com que alguns tenham que se deslocar a outros lugares mais brandos e pacíficos para sua existência.

Para que se compreenda melhor o artigo em questão, o desmembramento de seus tópicos se faz necessário, pois cada um deles é de suma importância para criarse o nexo textual. O primeiro deles discorre sobre quem são os direitos fundamentais e a necessidade de se pensar em políticas públicas de promoção do princípio da igualdade, inclusive para a população LGBT. No segundo tem-se o tratamento conceitual do que seja refugiados, qual o conceito que os define e quando surgiram na história, como também quando se destacaram por fim. Há também quando e como são definidos pelo estatuto criado, a fim de nomeá-los. Além disso, a disposição sobre qual o órgão responsável pela proteção dos mesmos e quais os dados mais recentes que servem de ilustração.

Já no terceiro item, é tratado, de forma específica, quem são os refugiados LGBTs e quem são os próprios pertencentes a esta sigla, para um ponto de partida inicial. Inclui-se, da mesma forma, como estes foram vistos ao longo dos anos - de uma forma social - e, principalmente, como são vistos agora, que acaba por envolver todo o preconceito e desigualdade em torno deles.

$\mathrm{Na}$ quarta parte são citados os direitos e garantias fundamentais do LGBTs refugiados, tema central do estudo em questão, e se aplica também àqueles que não estão na situação de refúgio, inclusive, dentro do âmbito nacional brasileiro.

Por fim, mas não menos importante, são observados os casos concretos em torno dos refugiados LGBTs, nos dias atuais, com a adição de dados numéricos, assim como em outros pontos do artigo, e relatos de situações sofridas pelos mesmos, para fincar, de maneira clara e explícita, os fundamentos legais, argumentos e informações expostas anteriormente. 


\section{OS DIREITOS E GARANTIAS DOS LGBTS}

Como assinala Cambi, o direito não pode ficar engessado aos métodos arcaicos, engendrados pelo pensamento iluminista do século XVIII, o pensar o direito deve passar por um aprimoramento para que a sua concretização não fique presa a institutos inadequados aos fenômenos contemporâneos e, assim, não se dissocie da realidade, frustrando seu escopo fundamental de abordar a condição humana nas múltiplas e complexas relações sociais, políticas e econômicas (CAMBI, 2008, p. 139172).

A superação histórica do jusnaturalismo e o fracasso político do positivismo abriram caminho para um conjunto amplo e ainda inacabado de reflexões acerca do Direito, sua função social e sua interpretação. $O$ pós-positivismo (neoconstitucionalismo) busca ir além da legalidade estrita, mas não despreza o direito posto, procurando empreender uma leitura moral do Direito, mas sem recorrer a categorias metafísicas. A interpretação e aplicação do ordenamento jurídico hão de ser inspiradas por uma teoria de justiça, mas não podem comportar voluntarismos ou personalismos, sobretudo os judiciais. No conjunto de ideias ricas e heterogêneas que procuram abrigo neste paradigma em construção, incluem-se a atribuição de normatividade aos princípios e a definição de suas relações com valores e regras, a reabilitação da razão prática e da argumentação jurídica, a formação de uma nova hermenêutica constitucional, e o desenvolvimento de uma teoria dos direitos fundamentais edificada sobre o fundamento da dignidade humana. Nesse ambiente, promove-se uma reaproximação entre o direito e a filosofia (BARROSO, 2005, p. 13).

Os Direitos Humanos Fundamentais compõem um construído axiológico, fruto da nossa história, de nosso passado, de nosso presente, fundamentado em um espaço simbólico de luta e ação social (PIOVESAN, 2005, p. 43-56). Costuma-se identificar três dimensões ou gerações de direito fundamentais, as quais se coexistem harmonicamente. São os direitos individuais, os direitos sociais e os direitos de fraternidade. A primeira geração alcança os direitos individuais e políticos, que são verdadeiros direitos de defesa, impondo limites à ação estatal. Tais direitos foram consagrados no Bill of Rights of Virginia, de 12 de junho de 1776, fruto da revolução 
americana, na declaração Francesa de direitos do homem e do cidadão, de 26 de agosto de 1789, e nas dez primeiras emendas à Constituição Americana, que entraram em vigor em 1791. A segunda Geração corresponde aos direitos sociais, econômicos e culturais, que são o direito à saúde, à educação, à previdência social, que exigem um facere do Estado, vale dizer uma ação positiva com o fim de propiciar melhores condições de vida (lato sensu) à pessoa humana e diminuir as desigualdades sociais. Como marcos fundamentais dessa geração, podem ser mencionadas as constituições do México de 1917 e a alemã de Weimar de 1919. A terceira geração alcança os direitos difusos, que rompem à individualidade do ser humano para abarcar grande parcela do grupamento ou a própria espécie, do que é exemplo o meio ambiente (GARCIA, 2006, p. 83-111).

Ante o exposto, levando em consideração os novos paradigmas e ao esbarrar com a grande quantidade de direitos definidos e garantidos em inúmeros instrumentos jurídicos, internacionais ou nacionais, assinala Bonavides (2008) que o problema principal do direito constitucional contemporâneo não está mais em juridicizar o Estado Social, até porque a Constituição de 88 imprimiu uma latitude sem precedentes aos direitos sociais, dotados agora de uma substantividade nunca vista nas cartas constitucionais anteriores, pois o problema fulcral encontra-se em como estabelecer meios para efetivar esses direitos. Ainda, segundo Trindade (1998, p. 21-163) há a necessidade de uma efetividade social dos Direitos Humanos, ou seja, a criação de instrumentos jurídicos para levá-los a prática.

Portanto, é possível entender que se deve ao Estado o desenvolvimento de instrumentos como as políticas públicas voltadas a estender a todos os indivíduos os direitos fundamentais, incluindo os direitos sociais (SCHIER, 2002), inclusive o direito a educação, se baseando em ações afirmativas para alcançar grupos mais marginalizados e alvos de discriminação, tal qual o caso da população LGBT, como será demonstrado no desenvolver do trabalho.

A raça humana é diferente e desigual, já em sua essência. Na esfera biológica, cada pessoa possui seus traços únicos, sendo um ser, por excelência, único. Também na esfera sociológica diferenças foram construídas e profundamente enraizadas em nossa cultura, o que também difere os povos como sendo únicos. Seja por motivo 
natural ou social, a humanidade é, por excelência, diferente e desigual (CONCl; AVOGLIO, 2008). Entretanto, o ideal de estabelecer uma sociedade igualitária a muito vem sendo buscado por toda a história da humanidade, mas em que constitui tal igualdade, já que somos diferentes por excelência?

O jusfilósofo Bobbio (1996) nos apresenta que a busca pela igualdade é um desejo de índole moral socialmente e politicamente almejado. Nestes traços, observase que a igualdade constitui um anseio de bem-estar social, no qual os indivíduos apresentem-se aptos a terem seus direitos respeitados e de serem tratados igualitariamente. Mas, tal aspecto se apresenta de natureza puramente teóricofilosófica, buscando uma mera conceituação, no entanto, para o presente trabalho é coerente analisar a igualdade como um direito disposto na Constituição Federal.

O princípio da igualdade constitui o signo fundamental da democracia (SILVA, 2006), sendo uma norma de direito fundamental que confere aos indivíduos o direito à igualdade de tratamento, tendo a característica de um direito subjetivo, sendo um princípio objetivo que se projeta sobre todo o ordenamento jurídico, com aplicabilidade imediata (CF, art. $\left.5^{\circ}, \S 1^{\circ}\right)$, imune ao poder constituinte reformador (CF, art. $60, \S 4^{\circ}$, IV) e, portanto, ocupante de uma posição preferente na ordem jurídica. Apresenta que o princípio da igualdade é uma norma de direito fundamental, em forma de cláusula geral, onde vincula todos os poderes públicos (Legislativo, Executivo e Judiciário) e confere aos indivíduos o direito fundamental à igualdade de tratamento e o direito fundamental ao tratamento isonômico (STEINMETZ, 2004).

As constituições - inclusive a brasileira - estabelecem que todos são iguais perante a lei, apresentando, assim, a face formal do princípio da igualdade, onde, se pode afirmar que a lei e sua aplicação deva tratar todos da mesma forma, sem distinção de grupos, ou seja, as normas jurídicas devem ser cumpridas (ALEXY, 2008; MORAES, 2002). A igualdade formal, já foi alvo de desenvolvimento de Kelsen, o qual leciona:

[...] compreende-se como de per si evidente que a exigência ou postulado de que todos os homens sejam tratados por igual, ou seja, de que não se deve fazer menção de nenhuma das desigualdades de fato existentes, qualquer que seja o conteúdo que possa ter 0 tratamento conforme a norma pressuposta pela norma de justiça, 
conduz consequências absurdas [...] Não é possível deixar de lado todas as desigualdades em toda e qualquer espécie de tratamento. Certas desigualdades têm de ser tomadas em consideração. Trata-se apenas de saber quais as desigualdades que devem ser desprezadas e quais os indivíduos que, portanto, podem ser considerados como iguais (KELSEN, 1994, p. 53).

Portanto, observa-se que o enunciado Aristotélico de simplesmente "tratar todos iguais perante a lei" é insuficiente para aplicar o princípio da igualdade nas relações sociais, sejam elas de direito público ou privado. Alexy leciona que

Se o enunciado geral de igualdade se limitasse ao postulado de uma práxis decisória universalizante, o legislador poderia, sem violá-lo, realizar qualquer discriminação, desde que sob a forma de uma norma universal, o que é sempre possível. A partir dessa interpretação, a legislação nazista sobre judeus não violaria o enunciado 'os iguais devem ser tratados igualmente (ALEXY, 2008, p. 394).

É importante relembrar que o Tribunal de Nuremberg marca a decadência do positivismo jurídico, que é inaugurada na tendência autoritária pela qual os chefes de estado se apoiaram em meados do século XX para proferir abominações, se escondendo por de trás do direito positivo, exemplos como o nazismo na Alemanha e o fascismo na Itália, que colocaram o medo e a intolerância na sociedade pela lei, tendo, os responsáveis por essas, utilizado a proteção da lei como argumento no Tribunal, para tentarem esquivar-se da condenação.

Então, utilizar a igualdade como postulado universal, pouco adiantaria, pois autorizaria a discriminação, como nos exemplos dados por Canotilho (1993, p. 588), onde uma lei determina que, "todos os indivíduos de raça judaica devem ter sinalização na testa; todos os indivíduos de 'raça negra' devem ser tratados 'igualmente`em ‘escolas` separadas das dos brancos”, observa-se que tanto negros como judeus estão sendo tratados de forma igual, embora, de forma discriminatória.

Ademais, ao observar alguns artigos da Constituição Federal, pode-se concluir que ela mesma apresenta normas que excetuam o disposto da igualdade formal ou perante a lei. No art. $7^{\circ}, X X X E X X X I$, vêm regras de igualdade material, regras que proíbem distinções fundadas em certos valores, ao vedarem diferença de salários, de exercício de funções e de critério de admissão por motivo de sexo, idade, cor ou 
estado civil e qualquer discriminação no tocante a salário e critérios de admissão do trabalhador portador de deficiência. A previsão, ainda que programática, de que a República Federativa do Brasil tem como um de seus objetivos fundamentais reduzir as desigualdades sociais e regionais (art. $3^{\circ}, \mathrm{III}$ ), veemente repulsa a qualquer forma de discriminação (art. 3ำ IV), a universalidade da seguridade social, a garantia ao direito à saúde, à educação baseada em princípios democráticos e de igualdade de condições para o acesso e permanência na escola, enfim a preocupação com a justiça social como objetivo das ordens econômicas e social (arts. 170, 193, 196 e 205) constituem reais promessas de busca da igualdade material (SILVA, 2006).

Torna-se assim, necessário repensar o valor da igualdade, a fim de que as especificidades e as diferenças sejam observadas e respeitadas. Somente mediante essa nova perspectiva é possível transitar-se da igualdade formal para a igualdade material ou substantiva (PIOVESAN, 2003).

Portanto, conclui-se que a igualdade deve buscar uma aplicação material, ou seja, utilizar medidas que possibilitem sua concretização na sociedade e não se apresentar como um critério universalizante, não interpretativo, do qual vincula apenas o legislador.

Assim como todos os outros cidadãos existentes em todo o mundo, a população LGBT também é detentora dos vários direitos e garantias fundamentais presentes nos documentos jurisdicionais, justamente pelo fato de não poder haver distinção entre qualquer ser humano.

Internacionalmente, há, como maior dos exemplos, os Direitos Humanos, criados em 1948, pela ONU, que garantem a todos os homens, independente de raça, idioma, sexo, religião, nacionalidade, etnia ou qualquer outra condição que exista inerente a ele, o direito à liberdade - tanto a de opinião como a de expressão - à vida, o direito à educação, ao trabalho, entre tantos outros.

Já no âmbito nacional, os LGBTs não possuem leis próprias e feitas especificamente a eles, entretanto, é encontrado no artigo $5^{\circ}$ da Constituição Federal Brasileira, em seu caput, que: 
Todos são iguais perante a lei, sem distinção de qualquer natureza, garantindo-se aos brasileiros e aos estrangeiros residentes no País a inviolabilidade do direito à vida, à liberdade, à igualdade, à segurança e à propriedade. [...].

Tal trecho possibilita dizer que não deve ser levado em consideração se o cidadão nasceu em solo brasileiro ou não; habitando o país, ele terá direitos básicos à sobrevivência e respeito mínimo, para que sua dignidade não seja afetada - o que faz com que haja uma ligação direta com o Princípio da Dignidade da Pessoa Humana. É dito por Soares (2010) que tal princípio é fundamental, pois

[...] vivendo em sociedade e procurando o seu bem, o homem acaba compreendendo a necessidade racional de respeitar em todo o homem uma pessoa, condição essencial para que também se possa afirmar como pessoa. Sendo assim, a ideia de Justiça, liga-se, de maneira imediata e necessária, à ideia de pessoa humana (SOARES, 2010, p. 130).

Ou seja, o LGBT, mesmo não tendo uma legislação exclusiva de proteção a ele, deveria sentir-se seguro e protegido pelo descrito e provido pela Carta Maior, pois ela relata todos os direitos essenciais para se viver em sociedade, sendo, teoricamente, o suficiente. Mas sabe-se que a realidade não é tão parecida com ela.

Como complemento aos direitos dados ao LGBTs, no Brasil, e agora, em um panorama melhor, tem-se, como aparato jurídico, a permissão para o casamento entre pessoas do mesmo sexo. Esta conquista, tanto para a população LGBT tanto para sociedade como um todo, completa, no ano de 2018, 5 anos de existência. Desde a Resolução n. 175/2013 do Conselho Nacional de Justiça (CNJ), os cartórios foram obrigados a realizar tal ato civil, agora devidamente legalizado. Ao menos 15 mil casamentos já foram realizados ${ }^{4}$ e, só no ano de 2015, aconteceram, aproximadamente, 1/3 deles. Isso mostra que, apesar de algumas situações em que o LGBT ser desrespeitados e conhecidamente estarem em algumas desvantagens, ainda há o que se comemorar e esperar como bons resultados. Acima de tudo, é importante frisar que não se trata apenas de um êxito para a população referida em

\footnotetext{
${ }^{4}$ Dados coletados até o ano de 2017, quando a pesquisa foi realizada.
} 
si. Trata-se de mais uma etapa vencida no caminho da igualdade entre todos os cidadãos.

\section{O QUE SÃO REFUGIADOS}

A Organização das Nações Unidas (ONU), criada no ano de 1948, pós Segunda Guerra Mundial, é a maior organização internacional, desde então, responsável por resolver diversos conflitos de caráter humanitário, podendo envolver mais de um país ou não. E foi ela que, no ano de 1951, deu mais atenção ao tema e tratou da questão sobre os refugiados. Foi somente após a Segunda Grande Guerra que os refugiados finalmente foram reconhecidos e entraram, permanentemente, no contexto sócio-político mundial.

Para antes deste marco, alguns pesquisadores acreditam que os refugiados existam desde a Antiguidade, mais especificamente no antigo Egito, mas que, somente a partir do século XV, começaram a aparecer de forma mais sistemática, sendo assim, a razão pela qual se diz este sendo o século de aparição dos refugiados e a existência da temática em si (JUBILUT, 2007).

Porém, apenas com o Estatuto do Refugiado, redigido pela ONU, como dito anteriormente, na Convenção das Nações Unidas, que se conceituou que refugiado é a pessoa perseguida - com fundado temor de perseguição - por motivos de raça, religião, nacionalidade, pertencimento a grupo social ou opiniões políticas. Em outras palavras, é a pessoa que tem seus direitos e garantias ameaçados por determinada característica que possui consigo, tendo que, na maioria das vezes, abandonar seu lar em busca de paz e compreensão social.

Mesmo com a presença da ONU, mundialmente atuante, e com o passar dos anos, em que ela tem oferecido cada vez mais respaldo a eles, o que mais se espanta é que o problema dos refugiados tem crescido de forma significativa e que a globalização - que se pode entender, neste caso específico, como o poder do acesso, de ir e vir de um país a outro sem maiores dificuldades - é que acaba os salvando de problemas ainda maiores e posteriores aos que possui em seu país natural, como veremos a seguir. 


\subsection{O PAPEL DO ACNUR}

Para contribuir e fazer com que a ONU direcionasse esforços de maneira adequada, atendendo de forma plena, ou pelo menos em sua teoria, às necessidades deste, relativamente, novo grupo, identificado como refugiados, foi criada pela mesma o Alto Comissariado das Nações Unidas para os Refugiados (ACNUR), em 1950, antes mesmo do Estatuto do Refugiado ser criado e homologado. Além da preocupação pelo bem-estar dos cidadãos mencionados, o ACNUR tem como responsabilidade e papel principal a proteção dos mesmos e das populações deslocadas por guerras, conflitos e perseguições.

Conforme o site oficial do ACNUR, em pesquisas realizadas até junho de 2017, 65,6 milhões de pessoas estão deslocadas em todo o mundo, configurando cerca de $10 \%$ da população mundial. Desse total, 22,5 são refugiados, sendo 17,2 sob o mandato do ACNUR e 5,3 milhões de refugiados palestinos registrados pela UNRAW (Agência das Nações Unidas de Assistência aos Refugiados da Palestina no Próximo Oriente). 28.300 mil pessoas, todos os dias, são obrigadas a abandonar suas casas devido a conflitos e perseguições sofridas a elas.

Sobre a questão dos refugiados e a assistência dada a eles:

Acolher os refugiados não é apenas um ato de solidariedade, mas tem a transcendência de um conceito humanitário que vem sendo construído há décadas. Ao contrário de muitos outros sistemas de proteção dos direitos humanos que ganharam uma convenção base e um órgão para sua implementação, o dos refugiados foi construído gradualmente e afirmando-se a cada nova conquista institucional para responder às necessidades das vítimas da perseguição e da intolerância (JUBILUT, 2007, p. 17).

Ela manifesta que é de extrema urgência e necessidade reverter a propensão de diversos países em criar políticas e legislações progressivamente mais restritas para o refugiado, dizendo que ele pode vir a ser um potencial terrorista ou até mesmo uma ameaça a ser coibida, tudo por uma causa maior, ou seja, em proteção aos Direitos Humanos. 


\section{REFUGIADOS LGBTS}

Antes da explanação sobre quem são os considerados refugiados LGBTs, é necessário ter por conhecimento o que significa esta sigla. Lésbicas, gays, bissexuais e transexuais/transgêneros são as pessoas que a compõe, sendo que, nos últimos tempos, mais uma letra tenha sido adicionada a ela, para maior abrangência e representatividade daqueles que a pertencem: os intersexuais, que correspondem à acrescida vogal $\mathrm{I}$.

De forma prática e em linhas gerais, por abrangência e analogia à definição dada sobre os refugiados logo no início do texto, os LGBTs refugiados são aqueles que se sentem na obrigação de fugir de determinado lugar, de sua origem, por insistente perseguição sofrida a eles, mesmo não sendo especificadamente mencionados nessa mesma definição.

Isadora Lins França é uma das autoras que incluem a letra I, supracitada, pelos motivos expostos, e afirma que os refugiados LGBTs pertencem a dois núcleos, teoricamente distintos, mas que convergem entre si no caso em tela, como dito por ela:

A categoria "refugiados LGBTl" [...] emerge da articulação entre dois campos de direitos, os relacionados ao refúgio e os relacionados a gênero e sexualidade. Trata-se de um contexto discursivo em que gênero e sexualidade se entrecruzam com a noção de "refugiados", encontrando paradas provisórias na nomeação de novos sujeitos, na categoria de vítimas, a merecerem a proteção do Estado (FRANÇA, 2017, pag. 43).

É importante salientar que alguns dos refugiados LGBT não são aceitos dentro de seus próprios países que são signatários do documento da Convenção das Nações sobre o tema, como é o caso do Arábia Saudita, Irã e Uganda.

De forma mais direta, e de acordo com a ONU, os LGBTs vêm se tornando uma importante e grandiosa parcela da população refugiada, apesar dela própria considerá-los como um "fenômeno novo" dentro do cenário dos refugiados, comparado a outros grupos coagidos. Tal aceitação torna-se necessária, primeiramente, por mais óbvio que pareça, por se tratar de seres humanos - e logo 
ver-se-á este ponto no tópico dos direitos dos LGBTs. E em segundo, pelo fato dos mesmos, por si só, já serem um dos grupos sociais que mais tem seus direitos fundamentais corrompidos. Diversos autores destacam que a homofobia é uma das expressões que mais fica em evidência quando o assunto é preconceito e discriminação nas lutas sociais e nos debates feitos publicamente, do século XX em diante (LOPES, 2007).

\section{REFUGIADOS LGBTS NA ATUALIDADE}

Exemplificando o que foi dito anteriormente, temos alguns casos concretos para ilustrar o assunto. O primeiro a ser citado é o de Lara (nome fictício): uma mulher moçambicana, de 33 anos, que teve que abandonar seu país de origem, procurando asilo em outro, para que pudesse expressar sua orientação sexual livremente, sem a interferência ou julgamento dos outros ao seu redor. A própria já chegou a acreditar nas explicações descabidas que a população local dá a sua orientação sexual, dizendo que o que recai sobre ela é algum tipo de doença, ou até a possessão por algum espírito maligno. Além das insinuações e olhares maldosos sobre Lara e aos LGBTs, assassinatos são cometidos, em casos extremos, tamanha intolerância encontrada.

Sobre a interpretação dos preconceituosos, vista acima, a respeito da homossexualidade de Lara ser uma doença,

Os atos homossexuais são vistos como sintomas de uma doença que acomete o indivíduo cuja presença identifica-o como 'homossexual', em contraposição a uma condição normal, tida como saudável, denominada de "heterosexualidade" (RIOS, 2011, p. 38).

De acordo com ele, tal pensamento é fruto do pensamento religioso, que dominou o mundo durante muito tempo em diversos assuntos, inclusive sobre a homossexualidade.

Além dela, foi encontrado no México, na cidade de Tenosique - parte sudeste do país e próximo à fronteira com a Guatemala -, um abrigo que recebe refugiados LGBTs. Quem administra o lugar é o frei Tomás Gonzáles Castillo, pertencente à 
ordem religiosa cristã de franciscanos. O albergue, conhecido como La 72, foi fundado, em 2011, com a intenção, não só de abrigar refugiados LGBTs, como todo e qualquer migrante da América Latina. Desde sua criação, o abrigo já ajudou e protegeu mais de 50 mil pessoas, oferecendo ajuda humanitária àquelas forçadas a fugir da violência, extorsão, recrutamento forçado e violações de direitos humanos, advindas de países como Honduras, El Salvador e Guatemala. Após o exemplo dado pelo frei, outras cidades como a Cidade do México e Guadalajara também criaram abrigos com o mesmo intuito. O local consegue acolher até 250 pessoas por vez, e as pessoas que o frequentam e por ali passam, são mães solteiras, menores e um número crescente de famílias. No ano de 2016, foram recebidas 43 pessoas refugiadas $L G B T I$, sendo que 13 delas solicitaram refúgio. Já no ano seguinte, acolheu-se 20 refugiados LGBT até a data de 30 de junho.

Uma mulher denominada Lilly (nome fictício), 20 anos, transexual, é uma das abrigadas pelo albergue La 72. Ela relata que, após caminhar dois dias ininterruptos, vindo de seu país de origem, Honduras, chegou a tão esperada zona de resguardo, e, pela primeira vez em anos, conseguiu dormir sua primeira noite horas e mais horas, sem se preocupar por manter-se a salvo.

Já Maria (nome fictício), uma estudante que trabalha no local, voluntariamente, em uma equipe mexicana com esse propósito, diz que, primeiramente, a regra dada às pessoas que ali chegam é que a violência não é tolerada, tão pouco a discriminação, pois uma leva à outra. E que, independentemente de gênero ou idade, todas as pessoas LGBT que procuram por ajuda ali, são socorridas igualmente.

Um estudo realizado pela Universidade de Rutgers, no estado de Nova Jersey, Estados Unidos, e publicado no Child Abuse \& Neglet, jornal internacional e interdisciplinar que discorre sobre os mais variados assuntos, como ele próprio dispõe: "o bem-estar infantil, saúde, ajuda humanitária, justiça, saúde mental, saúde pública e sistemas de serviço social.", e, principalmente, voltado para os abusos infantis que acontecem ao redor do mundo, relatou que migrantes LGBTs, vindos de países como a Nigéria, Coreia do Sul, Nicarágua, Rússia, entre outros, que conseguiram refúgio ou asilo no Canadá ou nos Estados Unidos, narraram abusos vindo de seus cuidadores, pais, amigos e funcionários da escola (professores e administradores) do país de onde 
vieram. Inclusive, com exceção de apenas quatro dos adolescentes recolhidos, contaram que os abusos se iniciaram quando os aliciadores descobriam que se tratavam de crianças homossexuais. E mais uma vez houve a tentativa de outras pessoas, neste caso, dos familiares, em "mudar" esses jovens, colocando, relacionando o assunto à religião, assim como no caso citado de Lara. Entrando na puberdade, é comum que estes possuam estratégias para impor comportamentos entendidos como corretos aos seus entes. Os migrantes disseram que, frequentemente, eram obrigados a orar, ler a Bíblia ou encontrar-se com membros da igreja a fim de "curá-los".

\subsection{OS REFUGIADOS LGBTS NO ÂMBITO NACIONAL}

Uma das maiores pesquisadoras sobre os Refugiados LGBTs atualmente, e que também inclui a nomenclatura "Intersexuais" na sigla, diz que o Brasil é, ao mesmo tempo, um dos países que mais recebe imigrantes LGBTI em todo o mundo, inclusive, pactuado com a ONU, mas tem uma situação contraditória internamente, sendo aquele que a LGBT-fobia está infiltrada não só na sociedade, mas também no órgão estatal. Em outras palavras, e concluindo logo após, diz que os refugiados brasileiros fogem de um país que, de forma ativa, defende as questões pertencentes aos LGBTI no âmbito Internacional, mas que também cria a eles a situação do refúgio (GORISCH, 2016).

Ainda sobre os dados brasileiros, O CONARE (Comitê Nacional para os Refugiados), - comissão interministerial, feita e administrada pelo Ministério da Justiça do Brasil, e também considerado um organismo público responsável por recepcionar solicitações de refúgio, determinando se aqueles que solicitam possuem as condições necessárias para serem reconhecidos como refugiados -, afirma que existem, no país, 8.863 refugiados reconhecidos pela $(\mathrm{ONU}, 2016)^{5}$. No ano anterior, haviam 12.668 solicitações de refúgio para julgamento, e somente $0,85 \%$ delas mostraram fundamentos de perseguição por pertencer a determinado grupo social. Em notícia do

\footnotetext{
${ }^{5}$ Dados de abril de 2016.
} 
mês de março de 2015, o ACNUR apontou que existiam 18 refugiados reconhecidos no Brasil por conta da orientação sexual e/ou identidade de gênero que possuíam e também outros 23 pedidos com o mesmo embasamento (ONU, 2015).

\section{CONCLUSÃO}

É de fácil compreensão que os refugiados, apesar de serem conhecidos, por assim dizer, desde o século XV e terem seus direitos garantidos em meados da metade do século XX sofrem, ainda hoje, tamanha injustiça e maus tratos, além da lenta evolução social da humanidade para aspectos que visem o bem-estar social do próximo, pela demora da importância dada ao tema. Apenas cinco séculos depois do descobrimento de sua existência, como visto aqui, medidas de caráter humanitário, jurídico e atitudes organizacionais, permitindo a participação e envolvimento de várias nações, começaram a ser tomadas. Antes disso, havia uma situação sem solução e sem perspectiva de melhora.

No caso dos refugiados LGBTs, personagens centrais da pesquisa, a situação só se agrava, pois além de serem refugiados e sofrerem todas as sanções impostas pela sociedade num panorama geral, ainda precisam combater o preconceito também sofrido pela orientação sexual que possuem, sendo este um outro problema a ser discutido a posteriori.

Diferente e relevante ponto a ser levantado, complementando o que foi dito no primeiro parágrafo deste tópico, é a importante atuação e compromisso da ACNUR, entre outros abrigos e lares com igual fim do mesmo, não só com os refugiados LGBTs, como também com todos aqueles que dela necessitam, estando nessa condição.

Já os direitos e garantias considerados fundamentais aos refugiados, de modo geral, que se aplicam e abrangem de forma tácita aos que também pertencem à comunidade LGBT, existem, mas não são respeitados da maneira que se espera. Tanto nacional como internacionalmente, a aplicação prática aguardada dos mesmos e que garante que os refugiados LGBTs tenham sua dignidade e integridade preservadas, são visivelmente infringidos e violados, apesar da concessão dada a 
eles em poderem se casar, o que alivia apenas um dos lados desse gigantesco disparate.

Os casos de refugiados LGBTs expostos, há de se lembrar, só enfatizam e provam o quanto a conjuntura de tais pessoas precisa ser revista, para que atitudes de desafeto, falta de cuidado e atenção e interpelação de direitos para com eles sejam eliminadas de vez.

Portanto, conclui-se que explanar sobre os refugiados LGBTs - e também dos refugiados como um todo -, é uma questão que envolve diversos problemas, conexos, unidos, e aqui destrinchados, na intenção inicial de se desenvolver um específico - os LGBTs -, mas que, assim como o problema deste tipo de refugiados, os outros precisam ser sanados no mesmo grau de competência de resolução do citado.

\section{REFERÊNCIAS}

A luta de refugiados que pedem asilo por sua orientação sexual. Disponível em: $<<$ https://www.huffpostbrasil.com/2016/01/04/a-luta-de-refugiados-que-pedem-asilopor-sua-orientacao-sexual_a_21691398/>. Acesso em 03 mai. 2018.

Abrigo mexicano acolhe pessoas refugiadas LGBTI. 2017. Disponível em: <http://www.acnur.org/portugues/2017/08/31/abrigo-mexicano-acolhe-pessoasrefugiadas-Igbti/>. Acesso em: 13 abr. 2018

\section{BANDEIRA, Regina. Casamento homoafetivo: norma completa quatro anos} 2017. Disponível em: <http://www.cnj.jus.br/noticias/cnj/84740-lei-sobre-casamentoentre-pessoas-do-mesmo-sexo-completa-4-anos>. Acesso em: 03 mai. 2018.

BRASIL. Constituição, 05 de outubro de 1988. Constituição da República Federativa do Brasil. Brasília, DF: Senado Federal, 2016.

CHARLEAUX, João Paulo. Qual o lugar dos refugiados gays no mundo. 2016. Disponível em: <https://www.nexojornal.com.br/expresso/2016/04/22/Qual-o-lugardos-refugiados-gays-no-mundo>. Acesso em: 19 abr. 2018.

Dados sobre Refúgio. 2017. Disponível em: <http://www.acnur.org/portugues/dados-sobre-refugio>. Acesso em: 13 abr. 2018.

FRANÇA, Isadora Lins. Refugiados LGBTI": direitos e narrativas entrecruzando gênero, sexualidade e violência. 2017. Disponível em: $<$ http://www.scielo.br/scielo.php?script=sci_arttext\&pid=S010483332017000200307\&lng=en\&nrm=iso\&tlng=pt>. Acesso em 03 mai. 2018. 
GORISCH, Patrícia. O Brasil Como Estado De Origem Para Refugiados LGTBI: Contradição Entre Âmbitos Interno E Externo. 2016. Disponível em: <http://www.seminario2016.abri.org.br/resources/anais/23/1474655631_ARQUIVO_ Brasilcomoestadodeorigemedeasilopararefugiadoslgbti.pdf>. Acesso: 28 abr. 2018.

JUBILUT, Liliana. O Direito Internacional dos Refugiados: e sua Aplicação no Ordenamento Jurídico Brasileiro. São Paulo: Método, 2007.

LEMOS, Karen. Refugiados LGBTs sofrem com perseguição e preconceito até entre seus conterrâneos. 2017. Disponível em:

<http://noticias.band.uol.com.br/noticias/100000864596/refugiados-lgbts-sofrempreconceito-ate-entre-seus-conterraneos.html>. Acesso em: 01 fev. 2018.

LOPES, José Reinaldo de Lima. et al. Em defesa dos direitos sexuais. $1^{a}$ ed. Porto Alegre: Livraria do Advogado, 2007.

O que são os direitos humanos? Disponível em: <https://nacoesunidas.org/direitoshumanos/>. Acesso em: 13 abr. 2018.

RIOS, Roger Raupp. A homossexualidade no Direito. $1^{\mathrm{a}}$ ed. Porto Alegre: Livraria do Advogado, 2011.

SOARES. Ricardo Maurício Freire Soares. O princípio constitucional da dignidade da pessoa humana. 1a ed. São Paulo: Editora Saraiva, 2010. 